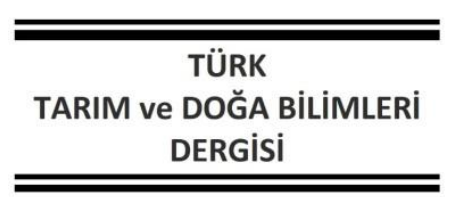

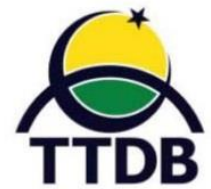

www.dergipark.gov.tr/turkjans

\title{
Gerçek Patates (Solanum tuberosum L.) Tohumu 101 (Nif) ve Farklı Melezlerinin Bazı Fiziksel Özelliklerinin Belirlenmesi
}

\author{
Zeynep DUMANOĞLU1*, Gülsüm ÖZTÜRK² \\ ${ }^{1}$ Bingöl Üniversitesi, Ziraat Fakültesi, Biyosistem Mühendisliği Bölümü, Bingöl \\ ${ }^{2}$ Ege Üniversitesi, Ziraat Fakültesi, Tarla Bitkileri Bölümü, İzmir \\ *Sorumlu Yazar: zdumanoglu@bingol.edu.tr
}

Geliş Tarihi: 24.03.2021 Düzeltme Geliş Tarihi: 10.06.2021 Kabul Tarihi: 29.06.2021

\section{Öz}

Patates (Solanum tuberosum L.) dünyada sevilerek üretilen ve tüketilen bir endüstri bitkisidir. Hem yumru hem de tohum olarak değerlendirilebilme özelliğine sahiptir. Ancak günümüzde patates üretiminde karşılaşılan sorunlar nedeniyle tohumdan üretim ön plana çıkmaktadır. Bu çalışmada, 2019-2020 yılları arasında, Ege Üniversitesi Ziraat Fakültesi Tarla Bitkileri Bölümü tarafından tescil edilen 101 (Nif) gerçek patates genotipi ile bu genotipin farklı melez kombinasyonlarından elde edilen tohumların bazı fiziksel özellikleri (şekilboyut, yüzey alan, izdüşüm alanı, ortalama aritmetik çap-geometrik çap, küresellik, bin dane ağırlığı) belirlenmiştir. Elde edilen verilere göre ebeveyn olarak kullanılan 101 (Nif) genotipinin özeliklerinin iyileştiği ve melezlerdeki mevcut diğer özelliklerinin de korunduğu belirlenmiştir. Ulaşılan bu sonuçların ileride yapılacak ıslah çalışmalarına ve mekanizasyon uygulamalarına alt yapı oluşturması amaçlanmıştır.

Anahtar kelimeler: Gerçek patates tohumları, Patates, Solanum tuberosum L., Tohum özellikleri, Tohum boyutları.

\section{Determination of Some Physical Characteristics of True Potato (Solanum tuberosum L.) Seed 101 (Nif) and Different Hybrids}

\begin{abstract}
Potato (Solanum tuberosum L.) is an industrial plant that is loved and consumed by the world. It can be evaluated as both a tuber and a seed. However, due to the problems encountered in potato production today, production from seed from tuber production comes to the seed. In this study, 101 (Nif) true potato genotypes and different hybrid combinations of this genotype, which registered by Ege University Faculty of Agriculture Field Crops Department, some physical characteristics (shape-size, surface area, projected area, mean area, arithmetic diameter-geometric diameter, sphericity, thousand-grain weight) of these seeds were determined between 2019-2020. According to the data obtained, it was determined that the characteristics of 101 (Nif) genotype used as parents improved and other existing characteristics of their crosses were also preserved. These results are intended to provide a basis for future improvement studies and mechanization practices.

Key words: True potato seeds, Potato, Solanum tuberosum L., Seed characteristics, Seed size.
\end{abstract}

\section{Giriş}

Patates (Solanum tuberosum L.), Solanaceae (Patlıcangiller) familyasına ait tek yıllık, heterozigot tetraploidlerden $(2 n=4 x=48)$, ticari olarak kültürü yapılan bir endüstri bitkisidir (Çakır, 2005; Öztürk, 2010; Oguz ve Yücel, 2020). İlk olarak Alp dağlarında patates bitkisinin kültüre alındığı daha sonra 16. yy'da İspanyolların bu bitkiyi Güney Amerika bölgesinden alarak hem kendi ülkelerine hem de İngiltere, İrlanda ve İskoçya başta olmak üzere tüm Avrupa'ya yaydıkları yapılan araştırmalar sonucunda belirlenmiştir (Abed ve Demirhan, 2018). Önceleri süs bitkisi olarak değerlendirilen patates zaman geçtikçe insanların beslendikleri ürünlerin arasına geçiş yapmıştır (Er ve ark., 2018). Patates bitkisi Türkiye'ye 1850 yılında Rusya ve Kafkaslar üzerinden gelmiştir (Ubeyitogulları, 2005). 
ilk olarak yabani patates (Solanum brevicaule) formunda olan bu bitki, kültüre alınarak farklı genotipleri oluşturulmuş ve üretimi gerçekleştirilmiştir. Patates bitkisi 200 tür ve 4000 'den fazla çeşitten oluşmaktadır (Spooner et al., 2005). Çok geniş bir alanda üretimi yapılan patates (deniz seviyesinden 4000 m yükseklikte 70 . Kuzey enleminden 50. Güney enlemine kadar) (Boydak ve Kayantaş, 2017), FAO tarafından "gizli hazine" olarak tanımlanmaktadır (Abed ve Demirhan, 2018). Mısır (Zea mays L.), pirinç (Oryza sativa L.) ve buğdaydan (Triticum aesitvum L.) sonra en fazla üretilen ve tüketilen üründür (Arvas ve ark., 2018). Türkiye'de yaklaşık 151 adet tescilli (141 adedi yurtdışından gelen ve geliştirilen çeşitler iken 10 adedi ülkemizdeki çeşitli kurum ve kuruluşlar tarafından geliştirilen yerli çeşitlerdir) patates çeşidi bulunmaktadır (Koyutürk ve Yılmaz, 2017). 2020 yılında yerli çeşit sayısı 25 olarak kayıt edilmiştir (BUGEM, 2020).

Dünyada patates üretimi yaklaşık 368 milyon ton (Oguz ve Yücel, 2020) civarında olup, Türkiye taze patates ihracatçısı konumundadır. 2019 yılında 80.6 bin ton patates (yumru) ithalatı yapılmasına karşın 145 bin ton patates ihracatı (\%99'u taze, \%0.6 tohumluk ve \%0.4 miktarda dondurulmuş) gerçekleştirilmiştir (BUGEM, 2020). TÜiK (2020) verilerine göre ise; 2018 yılında 4550 000 ton patates üretimi gerçekleştirilmiş, $2019 \mathrm{da}$ bu rakam 4979824 tona çıkmıştır.

Patates bitkisi, hem yumru hem de tohum ile üretim potansiyeline sahiptir (Öztürk ve Yıldırım, 2011). Son yıllarda yumru ile vejetatif üretimde karşılaşılan sorunlar (virüsler, hastalık ve zararlılar, depolama) nedeniyle fazla tercih edilmeyen, tohumdan patates bitkisinin yetiştirilmesi yeniden gündeme gelmiştir. Ancak üreticiler her yıl kaliteli ve sağlıklı üretim için tohumluk seçimleri yapmaktadır. Bilindiği üzere, tohumluk önemli bir tarımsal girdi faktörüdür. Bu nedenle, üreticilerin istediği dayanım özelliklerine (biyotik ve abiyotik çevre koşulları ile hastalık ve zararlılara karşı) sahip yeni genotiplerin geliştirilmesi amacıyla tohumluk üretim teknolojileri ile ilgili araştırmalar ve çalışmalar yapılmaktadır (Öztürk, 2010; Öztürk ve Yıldırım, 2014; Öztürk ve Polat, 2017).

Üreticilerin hedeflediği rekolteye ulaşabilmeleri için en önemli girdilerden birisi olan tohumluklar, mümkün olduğunca kaliteli ve sertifikalı olarak temin etmeleri ve kullanımları ile mümkündür. Tohumluk olarak üretilen ürünlerin ekimden hasada kadar hatta sonrasında ürün işleme basamaklarında da hep tohumların özelliklerine göre uygun alet, makine ve sistemler kullanılmaktadır. Bu şekilde, yaşanabilecek ürün kayıplarının önüne geçilmesi hedeflenmektedir. Tohum özellikleri ayrıca yapılan ıslah çalışmalarında da belirleyici bir faktör olarak yer almaktadır. Bu nedenle, tohumların kimlik bilgileri oluştururken bu verilerden de faydalanılmaktadır.

Bu çalışmada, 101 (Nif) patates genotipinin gerçek tohumları ile bu genotipin farklı melezlerinden (Agria X 101, Bettina X 101 ve Klon $6 / 7 \times 101$ ) elde edilen melez tohumlarının bazı fiziksel özelliklerinin istatistiksel olarak karşılaştırılması amaçlanmıştır.

\section{Materyal ve Metot}

Bu çalışma, 2019-2020 yıllarında Bingöl Üniversitesi Ziraat Fakültesi Biyosistem Mühendisliği ile Ege Üniversitesi Ziraat Fakültesi Tarla Bitkileri Bölümü ve Tarım Makinaları ve Teknolojileri Mühendisliği bölümlerine ait laboratuvarlarda yürütülmüştür. Çalışmada, genetik materyal olarak Ege Üniversitesi Ziraat Fakültesi Tarla Bitkileri Bölümünde yürütülen ıslah programı kapsamında elde edilen melez patates tohumları (Agria, Bettina ve 6/7 klonları) ile Ege Üniversitesi Ziraat Fakültesi Tarla Bitkileri Bölümünde tescil edilen 101 patates genotipinin gerçek patates tohumları kullanılmıştır. 101 (Nif) patates genotipi bol çiçek verme ve yüksek meyve bağlama kapasitesi nedeniyle tercih edilmiştir (Çizelge 1).

Tohumların özellikleri genotiplerine bağlı olup diğer genotiplerinden ayrıt edilebilmesi için geometrik ve şekil özelliklerinin belirlenmesi ve bu değerlere göre sınıflandırılması gerekmektedir (Çizelge 2) (Yağcıŏlu,2015).

Çizelge 1. Çalışmada kullanılan gerçek patates tohumlarının genotipleri

\begin{tabular}{cc}
\hline Gerçek Patates Tohumu & Pedigri $\left(\varphi \times \bigcirc^{\Uparrow}\right)$ \\
\hline 101 (Nif) & Agria X 101 \\
& Bettina X 101 \\
& Klon $6 / 7 \times 101$ \\
\hline
\end{tabular}

Çizelge 2. Tohumların geometrik ve şekil özelliklerine göre sınıflandırılması

\begin{tabular}{|c|c|c|c|}
\hline $\begin{array}{l}\text { Geometrik } \\
\text { özelliklerine } \\
\text { göre } \\
\text { tohumlar }\end{array}$ & $\begin{array}{c}\text { Tane } \\
\text { genişliği/ } \\
\text { Tane } \\
\text { uzunluğu } \\
\text { (b/a) } \\
\text { (mm) }\end{array}$ & $\begin{array}{c}\text { Şekil } \\
\text { özelliklerine } \\
\text { göre } \\
\text { tohumlar }\end{array}$ & $\begin{array}{l}\text { Uzunluk } \\
\text { (a), } \\
\text { Genişlik } \\
\text { (b), } \\
\text { Kalınlık (c) } \\
\text { (mm) }\end{array}$ \\
\hline Uzun & 0.6 & Yuvarlak & $a \approx b \approx c$ \\
\hline Orta & $0.6-0.7$ & Oval & $a / 3<b \approx c$ \\
\hline Kısa & $>0.7$ & Uzun & $c<b<a / 3$ \\
\hline
\end{tabular}


Çalışmada, 101 patates genotipi ile 3 farklı melez kombinasyona ait gerçek patates tohumlarının şekil ve boyut özelliklerinin belirlenmesi amacıyla, her bir genotipten rastgele olacak şekilde 100 'er adet tohum örneklenmiş, sonrasında bu tohumlar stereo mikroskop (Nexius Zoom-Image Focus $4.0 \quad$ v2.4) yardımıyla incelenmiştir (Dumanoğlu \& Mokhtarzadeh, 2020). Tohumlara ait uzunluk $(\mathrm{mm})$, genişlik $(\mathrm{mm})$ ve yüzey alan $\left(\mathrm{mm}^{2}\right)$ değerleri saptanmıştır (Dumanoğlu ve ark., 2021). Buradan elde edilen veriler aşağıda belirtilen eşitliklerden faydalanılarak tohumlara ait iz düşüm alanı $\left(\mathrm{mm}^{2}\right)$, ortalama aritmetik -geometrik çap $(\mathrm{mm})$ ve küresellik değerleri belirlenmiştir (Mohsenin, 1970; Alayunt, 2000, Kara, 2012). Ayrıca her bir genotipe ait olan tohumlar rastgele ve üçer tekrarlı olacak şekilde sayılarak Radwag AS 220.R2 analitik terazide $(0,0001 \mathrm{~g}$ hassasiyetine) tartılmış ve bin dane ağırıkları (g) belirlenmiştir (Dumanoğlu ve Geren, 2020).

İz düșüm alanı:

$$
A:(\pi * L * W) / 4
$$

$\mathrm{L}:$ Tohum tane uzunluğu $(\mathrm{mm})$

$\mathrm{W}$ : Tohum tane genişliği $(\mathrm{mm})$

A: İz düşüm alanı $\left(\mathrm{mm}^{2}\right)$

$\pi: 3.14$

Ortalama Aritmetik Cap:

$$
D:(L+W) / 2
$$

D: Tohuma ait ortalama aritmetik çap $(\mathrm{mm})$

L: Tohuma ait uzunluk değeri $(\mathrm{mm})$

$\mathrm{W}$ : Tohuma ait genişlik değeri $(\mathrm{mm})$

Ortalama Geometrik Cap:

$$
\text { Do: }\left(L * D^{\wedge} 2\right)^{1} / 3
$$

$\mathrm{D}_{0}$ : Tohuma ait ortalama geometrik çap $(\mathrm{mm})$

L: Tohuma ait uzunluk değeri (mm)

D: Tohuma ait ortalama aritmetik çap ( $\mathrm{mm}$ )

Küresellik:

$$
\Phi: D o / L
$$

$\Phi$ : Tohumun küresellik değeri

Do : Tohum ortalama geometrik çap (mm)

$\mathrm{L}$ : Tohum uzunluğu (mm)

\section{İstatistiksel Analiz}

Bu çalışmada, incelenen patates ve melez kombinasyonlarına ait bazı fiziksel (şekil-boyut, yüzey alan, ortalama aritmetik-geometrik çap, küresellik, bin tane ağırlığı) özellikleri belirlenmiştir. Tohumlar üçer tekrarlı olacak şekilde tesadüf parselleri deneme desenine göre incelenmiştir. Elde edilen veriler, SPPSS V.22 programı kullanılarak istatiksel olarak değerlendirilmiştir. Illk olarak, One-Way ANOVA testi ile tohumların genotip farklılıklarının $\mathrm{p}<0.05$ düzeyinde önemli olduğu belirlenmiş; sonrasında elde edilen verilere LSD testi uygulanarak gruplandırması yapılmıştır.

\section{Bulgular ve Tartışma}

Çalışmada elde edilen sonuçlara göre gerçek patates tohumlarının ortalama $0.853 \mathrm{~mm}$ uzunluğa, $0.607 \mathrm{~mm}$ genişliğe ve $0.407 \mathrm{~mm}^{2}$ yüzey alana sahip olduğu belirlenmiştir. 101 genotipine ait tohumların orta ve oval; melezleri olan Agria $\mathrm{X}$ 101 tohumlarının orta ve oval, Bettina X 101 tohumlarının ile Klon 6/7 X 101 tohumlarının kısa ve oval bir yapıya sahip oldukları belirlenmiştir. (Çizelge 3). Bu sonuç patates genotiplerinin şekil özellikleri Er ve ark. (2018)'ının belirtikleri ile örtüşmektedir. Agria X 101 genotipine ait tohumların genel olarak en yüksek değere sahip olduğu ve yapılan istatistiki inceleme sonucunda diğer genotiplerle farklı olarak gruplandırıldığı belirlenmiştir. Bu genotipi Bettina X 101 genotipi takip etmiştir. Ancak genotipler arasında en düşük değeri uzunluk değeri hariç (0.816 mm ile Klon 6/7 genotipi) olmak üzere 101 genotipinde ölçülmüş ve hesaplanmıştır. Tohumların bin dane ağırlıkları incelendiğinde ise; birbirlerine yakın değerlere sahip oldukları ancak Bettina X 101 genotipine ait tohumların diğer genotiplere göre belirgin bir ağırlık farkına sahip olduğu saptanmıştır (Çizelge 3).

$\mathrm{Bu}$ çalışmada incelenen tohumların küçük boyutlarda olmasının yanında hafif olma özelliğine de sahip olmaları nedeniyle mekanizasyon uygulamaları için bu tohumların mevcut ağırıklarının arttırııması ile özellikle ekim sırasında karşılaşılabilecek olumsuz durumların önüne geçilmesi mümkün olacaktır. Bunun için tohum özelliklerini iyileştirici yöntemlerden (pelletleme) faydalanılabilmektedir. Bu şekilde ağırlığı artan tohumların çevresel faktörlere bağlı olarak tohum yatağına yerleştirilmesinde karşılaşılabilecek sorunlar önlenmekte ya da en aza indirilebilmektedir. Ayrıca, tohumlar uygun depolama koşullarında bu şekilde daha uzun süre canlılıklarını koruyarak saklanabilmektedir.

\section{Sonuç ve Öneriler}

Bu çalışmada, Türkiye'de sevilerek tüketilen patates (Solanum tuberosum L.) bitkisine ait Ege Üniversitesi Tarla Bitkileri Bölümü tarafından tescil edilen101 (Nif) gerçek patates genotipi ile bu genotipin farklı melez kombinasyonlarından elde edilen tohumlar incelenmiştir. 101 (Nif) gerçek patates genotipi ve üç farklı melezine (Agria X 101, Bettina $X$ ve Klon 6/7) ait tohumların bazı fiziksel özellikleri belirlenmiş ve istatistiksel olarak karşılaştırılmıştır. Elde edilen verilere göre, 101 (Nif) gerçek patates tohumları ve ebeveyn olarak kullanıldığı melezlerin giderek daha iyi sonuçlara sahip olduğu, hem şekil özelliklerinin hem de bin dane ağırıklarını arttırdıkları belirlenmiştir. Bu 
sonuçlara bağlı olarak, yapılan ıslah çalışmasında 101 (Nif) genotipinin farklı genotiplerle melezlenmesi hem tohum özelliklerini iyileştirdiği hem de mevcut diğer özellikleri de iyileştirerek yeni çeşitlerin elde edilebileceğini göstermektedir. Bu çalışma ile incelenen ve ulaşılan sonuçların devam eden ve yapılacak olan yeni araştırmalara alt yapı oluşturacağı düşünülmektedir. Sadece ıslah çalışmaları açısından değil aynı zamanda mekanizasyon uygulamaları bakımından da patates tohumlarının uygun alet, makine ve sistemleri seçilerek üretim sürecine mevcut koşullara daha fazla dahil olması ayrıca bir sonraki üretim dönemi için tohumlukların ayrılmasında yine elde edilen bu verilerin olumlu katkı yapması amaçlanmıştır.

Çizelge 3. Gerçek patates genotiplerine ait tohumların bazı fiziksel özellikler

\begin{tabular}{|c|c|c|c|c|c|c|}
\hline \multirow{2}{*}{\multicolumn{2}{|c|}{ Tohum Özellikleri }} & \multicolumn{5}{|c|}{101 Genotipi ve melez kombinasyonları } \\
\hline & & 101 & $\begin{array}{c}\text { Klon } 6 / 7 \mathrm{X} \\
101\end{array}$ & Bettina X 101 & Agria X 101 & Ort. \\
\hline \multirow{2}{*}{ Uzunluk (mm) } & Ort. & $0.828^{\mathrm{bc}}$ & $0.816^{c}$ & $0.848^{b}$ & $0.919^{a}$ & 0.853 \\
\hline & Stdv. & 0.074 & 0.071 & 0.065 & 0.108 & 0.080 \\
\hline \multirow{2}{*}{ Genişlik (mm) } & Ort. & $0.563^{c}$ & $0.610^{\mathrm{b}}$ & $0.614^{b}$ & $0.642^{\mathrm{a}}$ & 0.607 \\
\hline & Stdv. & 0.056 & 0.066 & 0.066 & 0.071 & 0.065 \\
\hline \multirow{2}{*}{ Yüzey alan $\left(\mathrm{mm}^{2}\right)$} & Ort. & $0.367^{c}$ & $0.389^{b}$ & $0.408^{b}$ & $0.463^{\mathrm{a}}$ & 0.407 \\
\hline & Stdv. & 0.058 & 0.069 & 0.061 & 0.099 & 0.072 \\
\hline \multirow{2}{*}{ İzdüşüm alanı $\left(\mathrm{mm}^{2}\right)$} & Ort. & $0.367^{c}$ & $0.393^{b}$ & $0.410^{\mathrm{b}}$ & $0.467^{\mathrm{a}}$ & 0.409 \\
\hline & Stdv. & 0.058 & 0.069 & 0.065 & 0.097 & 0.072 \\
\hline \multirow{2}{*}{$\begin{array}{l}\text { Ortalama Aritmetik } \\
\text { çap }(\mathrm{mm})\end{array}$} & Ort. & $0.696^{c}$ & $0.713^{b c}$ & $0.731^{b}$ & $0.781^{\mathrm{a}}$ & 0.730 \\
\hline & Stdv. & 0.055 & 0.063 & 0.057 & 0.082 & 0.064 \\
\hline \multirow{2}{*}{$\begin{array}{l}\text { Ortalama Geometrik } \\
\text { Çap }(\mathrm{mm})\end{array}$} & Ort. & $0.089^{c}$ & $0.104^{b}$ & $0.109^{b}$ & $0.193^{\mathrm{a}}$ & 0.124 \\
\hline & Stdv. & 0.023 & 0.028 & 0.028 & 0.062 & 0.035 \\
\hline \multirow{2}{*}{ Küresellik } & Ort. & $0.107^{c}$ & $0.125^{b}$ & $0.127^{b}$ & $0.205^{a}$ & 0.141 \\
\hline & Stdv. & 0.022 & 0.027 & 0.027 & 0.043 & 0.030 \\
\hline \multirow{2}{*}{ Bin dane ağırlığı (g) } & Ort. & 0.450 & 0.430 & 0.580 & 0.450 & 0.483 \\
\hline & Stdv. & 0.005 & 0.003 & 0.005 & 0.005 & 0.001 \\
\hline
\end{tabular}

Çıkar Çatışması Beyanı: Makale yazarları arasında herhangi bir çıkar çatışması bulunmamaktadır.

Araştırmacıların Katkı Oranı Beyan Özeti: Yazarlar makaleye eşit oranda katkı sağlamıştır.

\section{Kaynaklar}

Abed, M.M., Demirhan, B. 2018. Patates bitkisine (Solanum tuberosum L.) genel bir bakış. Interntional Journal of Life Sciences and Biotechnology. 1(1):1-9.

Alayunt, F.N. 2000. Biyolojik Malzeme Bilgisi, Ege Üniversitesi Ziraat Fakültesi Tarım Makineleri Bölümü Ders Kitabı, Ege Üniv. Ziraat Fak. Yayınları No: 541.

Arvas, Y.E., Aksoy, H.M. Kaya, Y. 2018. Patates bitkisinde biyoteknolojik çalışmalar. Life Science and Biotecnology. 1(1):37-47.

Boydak, E., Kayantaş, B. 2017. Bazı patates (Solanum tuberosum L.) çeşitlerinin verim ve verime etkili parametrelerin belirlenmesi üzerine bir araştırma. Türk Doğa ve Fen Dergisi. 6(2):79-82.

Çakır, E. 2005. First report of potato wart diease in Turkey. Plant Pathology. 54:584.

BUGEM, 2020. Tarım ve Orman Bakanlığı Bitkisel Üretim/Ürün masaları/ Patates Bültenleri (https://www.tarimorman.gov.tr/BUGEM/, Erişim tarihi: 24 Aralık 2020).

Dumanoğlu, Z., Çaçan, E., Kökten K. 2021. Korunga (Onobrychis viciifolia Scop.) genotiplerine ait tohumların fiziksel özelliklerinin belirlenmesi. Journal of Anatolian Environmental and Animal Sciences. 6(1):18-24.

Dumanoğlu, Z. Geren, H. 2020. An Investigation on Determination of Seed Characteristics of Some Gluten-Free Crops (Amarantus mantegazzianus, Chenopodium quinoa Willd., Eragrostis tef [Zucc] Trotter, Salvia hispanica L.). Turkısh Journal of Agriculture-Food Science and Technology. 8(8), 1650-1655. 
Dumanoğlu, Z. Mokhtarzadeh, S. 2020. Türkiye'de Kültürü Yapılan Salvia Türlerine (Salvia hispanica L., Salvia tomentosa Mill. ve Salvia verticillata L.) Ait Tohumların Bazı Fiziksel Özellikleri, Türk Tarım ve Doğa Bilimleri Dergisi 7(3): 596-602.

Er, C., Uranbey, S. \& Başalma D. 2018. Nişasta ve Şeker Bitkileri. Ankara Üniversitesi Ziraat Fak. Yayınları. Yayın No: 1646, Ankara.

International Rules for Seed Testing (ISTA). 2007. International Rules for Seed Testing Book.

Kara, M. 2012. Biyolojik Ürünlerin Fiziksel Özellikleri, Atatürk Üniv. Ziraat Fakültesi Yayınları No: 242.

Koyutürk, Ö. Yılmaz G. 2017. Bazı patates genotipleri arasında yapılan melezlemelerde farklı rakım ve ortamların tohum tutma oranına etkileri. KSÜ Doğa Bilimleri Dergisi. 20 (Özel sayı):211-215.

Oguz, H.í. \& Yücel, D. (2020). Nevşehir illinde Patates (Solanum tuberosum L.) Yetiştiriciliğinin Ekolojik ve Sosyo Ekonomik Bakımdan Araştırılması. Türk Tarım ve Doğa Bilimleri Dergisi. 7(4):1159-1170.

Öztürk, G. 2010. Tohumluk patates üretiminde kullanılan mini ve mikro yumruların tarla performanslarının karşılaştırılması. Ege Üniversitesi Fen Bilimleri Enstitüsü Tarla Bitkileri Anabilim Dalı, Doktora Tezi, İzmir.

Öztürk, E. Polat, T. 2017. Tohumluk patates yetiştiriciliği ve önemi. Alınteri Zirai Bilimler Dergisi. 32(1):99-104.
Özturk, G. Yildirim, Z. 2011. Uniformity of potato minitubers derived from meristem cultures of nuclear seed stocks. Turkish Journal of Field Crops 16: 149-152.

Özturk, G. Yildirim, Z. 2014. Comparison of old and new clones of potato nuclear seed stocks for tuber uniformity in the greenhouse. Turkish Journal of Field Crops 19: 90-95.

Mohsenin, N.N. 1970. Physical Properties of Plant and Animal Materials. Gordon and Breach Science Publishers.

Spooner, D.M., McLean, K., Ramsay G., Waugh R. Bryan G.J. 2005. A single domestication for potato based on multilocus amplified fragment length polymorphism genotyping. Proceeding of the national Academy of science of the united States of America. 102(41): 14694-14699.

TÜik. 2020. Türkiye İstatistik Kurumu Bitkisel Ürünler: Yenilebilir Kök ve Yumrular (erişim:24.12.2020).

Ubeyitogulları, F. 2005. Hatay yöresinde yetiştirilen bazı patates çeşitlerinin fiziksel, kimyasal ve teknolojik özelliklerinin belirlenmesi. Mustafa Kemal Üniversitesi Fen Bilimleri Enstitüsü Gıda Mühendisliği ABD. Yüksek Lisans Tezi, Hatay.

Yağcıoğlu, A. 2015. Ürün İşleme, Ege Üniversitesi Yayınları Ziraat Fakültesi Yayın No: 517, Genişletilmiş 2. Baskı. 